\title{
Mechanism of Sustainability and Structure of Stakeholders in Regions
} Hiroshige Tanaka

The faculty of Economics at Chuo University, Tokyo, Japan.

Abstract: Global market and government failures might be possible to cause great crises for the global communities. To prevent the great crises global communities attempt to construct the sustainable mechanisms with integrated communication and incentives. This paper discusses that the second best solution of the sustainable mechanism can be achieved by employing the two indexes of the altruistic and risk coefficients. It is also demonstrated that the sustainable mechanism improves social welfare but affects differently performances of corporations. The corporations have the two types of stakeholders referred as positive and negative stakeholders according to the positive or negative information in their external benefits. The combination of the two stakeholders is formed by the feature of the corporation. The sustainability mechanism is proved to encourage activities in the positive stakeholder dominated corporation but to lower productions in the negative stakeholder dominated corporation. Consequently, the sustainability mechanism raises the communities to be connected with many positive stakeholder dominated corporations but shrinks the communities formed by influential corporations with dominant negative stakeholders. The new industrial revolution is anticipated to change the structure of the stakeholders. In particular, the sustainability mechanism to cope with the new industrial revolution is expected to grow selectively regions.

Keywords: Altruistic and risk coefficients, Positive and negative stakeholders, the new industrial revolution, Global sustainable mechanisms

\section{Introduction}

Since the last decade of the $20^{\text {th }}$ century the thought of the neo-liberalism has increased the influence as the globalized economies enlarged. In particular, the theory argues the benefit of enlarging market economies. However, the global financial crises have displaced a fear of unstable mechanism into the optimistic view on growth and prosperity in the global market economies. The enlarged markets have experienced to be vulnerable in the risk of the market and government failures. The two failures might spread the crises caused in one country over the global communities and project the insufficient provision of global pubic goods for the global community to restore sustainability. To prevent global communities from the great crisis, we should construct a mechanism to save both the global and local regions from the critical risks.

By the increasing pressure of social needs governments are forced to enact the legislations and regulations to restrain activities of domestic corporations and residents. The significant problems such as growth of aging population, urbanization and the new industrial revolution are possibly to increase the social needs for public services. The sustainability issues of global communities such as climate change problems create the social needs additionally. The swelling needs for the administration trend to lower the efficiency or the evaluation of governments.

The development of new industrial technologies such as AI and IoT facilitates the transborder transportation of both soft and hard types of products. Consequently, corporations are more likely to obtain opportunities to trade 
overseas beyond the governmental legislations and restrictions.

In the enlarged economies many corporations are more probable to turn down their performance by failures of compliance and M\&A. The corporations should take well communication with international and local regions in the contexts of environment, social custom, governmental legislations and restrictions and voluntary contributions. To be sustainable in the global communities, they do not only obey the rules of the market but also are obliged to perform social responsibility certainly. The efficient communication between the corporation and stakeholders could enhance the performance of the social responsibility. The improvement of global sustainability ought to be achieved in cooperation with the members concerned. In order to construct efficiently sustainable communities the corporation may be favorable to participate in the organizations to share the responsibility for global sustainability. To achieve the aim properly the corporation declares the performance openly and stakeholders evaluate it clearly to improve its performance. In 1973, Arrow $^{[2]}$ argues that the theoretical analysis of economics is effective to explore the corporate social responsibility. In 2001, Tirole ${ }^{[36]}$ discusses that the theory of incentive could improve researches on the corporative governance by focusing on the value of corporation. To pursue the process for sustainable community we are obliged to construct appropriate mechanism for this aim. In 2004, Tanaka ${ }^{[23]}$ provides a basic model to analyze the structure of sustainable community where the corporation could construct an efficient communication mechanism with multi stakeholders.

Tanaka ${ }^{[23]}$ provides the theoretical method that corporations and organizations are induced to reach sustainable situation with multi stakeholder cooperatively. This approach is referred briefly as the Tanaka method to simplify the notation in the following sections. As the market economies have been enlarging, multinational corporations and organizations observing the stakeholders becoming more various. In 2009, Tanaka ${ }^{[25]}$ argues that this theoretical model is applied for an explanation of instability in the global financial system. This paper concludes that the enlarging stake holders could influence sustainability of the global economies. In 2009, Tanaka ${ }^{[25]}$ argues that this theoretical model can explain a scheme of instability in the global financial system. Tanaka ${ }^{[26]}$ explores the restructure of global cites by extending this approach. Tanaka ${ }^{[26]}$ explores the restructure of global cites by extending this approach.

Greek Crisis, 2009-2015 focused on the cooperation in global financial system. Tanaka ${ }^{[30]}$ suggests the cooperative standard that we should reconstruct the financial system as a global public goods. PRI (Principles for Responsible Investment) declares the principles that the social responsible investments should consider the factors on environment, society and governance (UNEP FI and UN Global Compact ${ }^{[37]}$ ). In 2017, Tanaka ${ }^{[32]}$ provides a theoretical foundation that the mechanism of ESG (Environment Society and Governance) could contribute the sustainability of global communities. Tanaka ${ }^{[34]}$ argues that this method is applicable to regional governance.

The aim of this paper explores theoretically that the mechanism of sustainability could restructure each region differently in the two points. Firstly, although the mechanism should be introduced informally in global society, it influences differently on each region by depending on the characteristics in the inherent stakeholders. Secondly, the mechanism could be applicable for any region where the reconstruction caused by the new industrial revolution may be different. The sustainability principle indicates to reduce welfare losses for all regions but makes effects on many regions differently by depending on how the regional communities cooperate efficiently with the local industries.

This paper demonstrates that the two indexes presented by Tanaka ${ }^{[23]}$,altruistic and risk coefficients, could evaluate the efficiency of the mechanism and project the democratic process. This paper makes clear the two themes as main results. In the first, the mechanism of the governance that is available for only the altruistic coefficient in the two coefficients cannot achieve sustainable communities. The mechanism guided by the both indexes can achieve sustainability. In the second, the sustainability mechanism brings about the second best allocation. The analysis of welfare loss is possible to correct the welfare loss among stakeholders and to improve the quality of the governance.

To achieve the targets on sustainability, we construct the optimal conditions for sustainability by using altruistic coefficient and risk coefficient. We demonstrate 3 propositions. In Proposition 1, the decentralized mechanism for sustainability cannot achieve the first best solution. We should approach the sustainability of the second best to increase the social surplus. Proposition 2 argues that the sustainability of the second best is represented by mixing altruistic and risk coefficients. And the solution of sustainability cannot be attained by a single coefficient. Proposition 3 states that the second best solution of sustainability improves the communication and governance and raises the social welfare pro- 
duced by corporation in the regions. The balance of powers between positive and negative stakeholders influences on the vitalization of the region.

This paper is organized as follows. Section 1 states the theoretical framework of the paper. The sustainability mechanism is constructed by the theoretical and empirical researches regarding environmental and regional management, corporate governance, theory of incentives and corporative social responsibility. Section 2 implies that the integrated approach succeeds the proceeding researches and provides the theoretical foundation on the sustainability mechanism. This section demonstrates also that the altruistic coefficient could not work completely in the first best mechanism of sustainability. We exhibit the optimal condition of sustainability by the combination of altruistic and risk coefficients. We can prove that the second best mechanism of sustainability increases the social welfare more than the market solution. The mechanism makes effect to enhance or to decline the activities of corporation according to the relative influence between positive and negative stakeholders. Section 3 indicates that the balance of influences between positive and negative stakeholder influences the relation that the mechanism could bring about the vitalization of the region. In the new industrial revolution the scope of negative stakeholders group tends to decline and the effect to raise economies spreads over a relatively restricted area. Consequently, the effects to raise regional economies work not uniformly but diversify on the local vitalizations. Although uplifting moves of economies view largely in many sites, other regions might remain to suffer from chronical lowering trends.

\section{The theoretical framework for the sustainable mechanism}

\subsection{Communication and incentive scheme}

The accelerating innovation mainly in the ICT technologies is usually referred as the forth industrial revolution and expected to bring a great impact on the globalized economic society. As the globalization proceeds, the enlarged global markets have brought the corporation not only the increasing scope of stakeholders such as consumers, employers, community residents, supply chains, local governments but also the diversified social needs. The manufacturing corporation has pursued the scale merit of markets to lower the cost of the product. However, innovation of ICT technologies develops the mechanism to connect consumers and producers more directly and to lower the cost of distribution by obtaining accurate market information. The corporation to locate many offices overseas has become more influential on residents beyond the border of states and markets. The new technological innovation has created new service and knowledge industries and changed social structures to enhance instability on global communities. To weaken the damage of social impact in global communities, the mechanisms to aim at sustainability such as SDGs (Sustainable Development Goals) and ESG are constructed and promoted by the international organizations such as UN. The mechanism for sustainability could improve efficiency of governance by lowering social risk and by enhancing cooperation. Tanaka ${ }^{[32,34]}$ explores the theoretical foundation on the sustainability of the region by applying the Tanaka method on the global corporation. Considering that the similar reasoning is applicable for any corporation and organization and that the region forms the network system of the integrated organization, this paper explores the sustainable structure for the region. And the sustainability is proved explicitly to be achievable by the integrated system of voluntary and regulative initiatives.

In the beginning, it is appropriate for us to start the discussion by explaining the framework of the Tanaka method briefly. It is supposed that one multi national corporation has relation with n stakeholders. For example, stakeholders represent consumers, employers, stakeholders, residents, local governments and so on. To continue production ty $\mathrm{x}$ the corporation is not only required to obey the legislation and the regulation but also keep cooperation relation with many stakeholders. The corporation makes payment $t_{i}$ for stakeholder $i$, such as spends for environment preservation, penalty, tax, contribution for region and social responsible investment to add to market transaction. The corporation makes net profit $\Pi(x)$ from the market trade and at the same time receives the external evaluation $V_{i}\left(x, t_{i}\right)$ by the stakeholder i. The assumption of asymmetric information means that the corporation cannot make the evaluation of stakeholders accurately. To prevent market failure caused by the asymmetric information, regulation and requirement are constructed formally and informally such as code, standard, rationing. The effect to correct the skewness from 
asymmetric information is expressed by the altruistic co-efficient $\delta(1>\delta>0)$. The assumption that $\delta$ is bounded above by one describes that improving communication efficiency ought to confront with many restrictions. The corporation is assumed to recognize partially the evaluation of stakeholder i as $\delta V_{i}\left(x, t_{i}\right)$.

Voluntary contribution by the corporation is supposed to improve sustainability of the global communities. The corporation needs to obtain proper system of external evaluation to promote social responsibility. Stakeholder i is willing to take the effort for communication $\mathrm{y}_{\mathrm{i}}$ to open and share information among the corporation and stakeholders. Since the construction of the system in the community is required to prove the external evaluation, the total efforts for communication $\mathrm{y}=\mathrm{y}_{1}+\cdots+\mathrm{y}_{\mathrm{n}}$ is assumed to raise the efficiency of the evaluation system. The altruistic coefficient is expressed by increasing function of $\mathrm{y}, \delta^{\prime}(\mathrm{y})>0$.

The fine is imposed upon the corporation to obey compliance. And taxes are levied on the market transactions. The regulative initiatives are assumed to have the target to be achieved. The stakeholder $\mathrm{i}$, such as shareholders, institutions and NPO, expects for the corporation to achieve $\alpha_{i}\left(\alpha_{i}>0\right)$. The regulative initiative presents the incentive scheme for the sustainability by imposing the penalty $\Phi_{i}\left(\alpha_{i}-V_{i}\left(x, t_{i}\right)\right)$ on the corporation to be expressed by a positive value. When the corporation can contribute on infrastructure and vitalization of the region, the incentives are denoted by a negative values for penalties and a negative values for subsidy and donation of governments and agents. It is supposed that the target could not be achieved, and stated formally by the inequalities $\alpha_{i}-V_{i}\left(x, t_{i}\right) \geqq 0$.

Since stakeholder $\mathrm{i}$ determines $\alpha_{i}$, the corporation cannot estimate $\alpha_{i}-V_{i}\left(x, t_{i}\right)$ accurately. However, as the gap between the target and the evaluation increases, the incentive scheme should raise the penalty or decline the subsidy. Formally, the sustainability mechanism observes the communication enhancing the estimation of $\alpha_{i}-V_{i}\left(x, t_{i}\right)$. The sustainability mechanism makes the opportunity of learning to improve the communication process practically.

\subsection{Altruistic initiatives for sustainability}

Stakeholders are assumed to raise $\delta(y)$ to enhance sustainability of local and global communities. The variable y is represented by the quantitative index integrating communications between stakeholders and the corporation such as rationing, survey, research and so on. When the altruistic coefficient increases, the corporation brings more weight on the evaluation by the stakeholders to be named as "the social value of the corporation" and could perform risk management more efficiently. The social value of the corporation is one of the main pillars to fund the construction of the sustainability. We will explore that increment of the altruistic coefficient raises the social value of the corporation. Enhanced total payment y for the third party or organization to raise the altruistic coefficient induces the corporative decision making to reflect the social value as well as the private profit. The sustainability mechanisms such as ESG and SDGs attempt to develop the comparative measurement of the social cost of major corporations. The numbers of signature corporations for PRI are expressed by one index $y_{i}$. In this mechanism, the corporation is assumed to pay $t_{i}$ for stakeholder i according to the guiding rule prescribed by the sustainability principles.

Although the benefit of sustainability could be shared commonly by all stakeholders, the construction of mechanisms for sustainability brings the additional costs on the economies and the societies and is evaluated properly by the cost benefit analysis. Tanaka ${ }^{[24]}$ supposes that the mechanism attempts to maximize the conceived social value of the corporation to be stated by

$$
R V=\delta(y) \sum_{i=1}^{n}\left(V_{i}\left(x, t_{i}\right)-y_{i}\right)
$$

As the value of RV grows, the corporation pays more attention to the own conceived social value. Consequently, the corporation becomes to share the social needs with stakeholders positively. The evaluation of the corporation brings effort $y_{i}$ of stakeholder $i$ such as the costs to audit or to publish the survey. In the expression (1), the net value of evaluation for $i$ is exhibited by $V_{i}\left(x, t_{i}\right)-y_{i}$. Reminding that the inequality $\sum_{i=1}^{n} V_{i}\left(x, t_{i}\right)>R V$ holds, (1) is maximized for each $\mathrm{y}_{\mathrm{i}}$. The elasticity of altruistic coefficient with effort $\mathrm{y}$ is defined by $\varepsilon=\frac{\mathrm{y}}{\delta} \frac{\partial \delta}{\partial \mathrm{y}}$, and the independent effort among stakeholders is stated by $\frac{d y}{d y_{i}}=1$.

Considering that $(1)$ is rewritten by $\delta(y)\left(\sum_{i=1}^{n} V_{i}\left(x, t_{i}\right)-y\right)$, the optimal condition, 


$$
\frac{\partial \mathrm{RV}}{\partial \mathrm{y}}=0
$$

is transformed by

$$
\varepsilon=\frac{\delta}{\sum_{\mathrm{i}=1}^{\mathrm{n}}\left(\mathrm{V}_{\mathrm{i}}\left(\mathrm{x}, \mathrm{t}_{\mathrm{i}}\right)-\mathrm{y}_{\mathrm{i}}\right)} \frac{\mathrm{y}}{\delta}=\frac{\mathrm{y}}{\sum_{\mathrm{i}=1}^{\mathrm{n}}\left(\mathrm{V}_{\mathrm{i}}\left(\mathrm{x}, \mathrm{t}_{\mathrm{i}}\right)-\mathrm{y}_{\mathrm{i}}\right)} .
$$

It is supposed that the elasticity is constant. As the effort y to improve efficiency of communication is enhanced, net social value of the corporation $\sum_{i=1}^{n}\left(V_{i}\left(x, t_{i}\right)-y_{i}\right)$ increases. This implication notices that the communication process presented in this method facilitates to promote sustainability of both the corporation and the community. If the mechanism for sustainability could inform the corporation the social value of it definitely and publicly, it attempts to raise the own net social value. And the expression (3) refines the following implications. The larger the elasticity becomes, the greater net social value of the corporation is achieved by the identical effort. If the mechanism for sustainability improves the elasticity, the corporation increases the own net social value. However, the globalization of economies is possible to force the downward moves in the elasticity. To prevent the distorting trend the mechanism for the sustainability is required to enforce the function of communication.

The social value of the corporation is supposed to be greater than one. The assumption of asymmetric information on the evaluation by stakeholders is defined by the altruistic coefficient $\delta$ states the condition,

$$
\sum_{\mathrm{i}=1}^{\mathrm{n}} \mathrm{V}_{\mathrm{i}}\left(\mathrm{x}, \mathrm{t}_{\mathrm{i}}\right) \geq \delta \sum_{\mathrm{i}=1}^{\mathrm{n}}\left(\mathrm{V}_{\mathrm{i}}\left(\mathrm{x}, \mathrm{t}_{\mathrm{i}}\right)-\mathrm{y}_{\mathrm{i}}\right) \geq \delta \sum_{\mathrm{i}=1}^{\mathrm{n}} \mathrm{V}_{\mathrm{i}}\left(\mathrm{x}, \mathrm{t}_{\mathrm{i}}\right)-\mathrm{y} .
$$

The above expression (4) implies that the method using the effort variable y aims the objective function to be less than the first best social value of the corporation.

Proposition 1. The total effort y to raise altruistic coefficient makes effect to increase the social value of the corporation to be effective guiding index for sustainability. However, the effect of total effort y depends on the altruistic elasticity of $\varepsilon$. The corporation in the mechanism of the sustainability to be induced by only the altruistic coefficient without risk coefficient initiatives aims at lower social value than the first best sustainable value.

\section{Social surplus and sustainability}

\subsection{The construction of sustainability mechanism}

Performances of some major corporations in the regions are evaluated positively by the related regional economies. Inappropriate governance of the corporations sometimes make effect negatively on some stakeholders in the regional society and environment. The stakeholders are classified into positive and negative stakeholders according to the evaluated influence from the corporation. To develop the analysis the two types of stakeholders is defined precisely by (5). The positive stakeholders are denoted by $1, \ldots, \mathrm{n}_{1}$, and the negative stakeholders are numbered by $\mathrm{n}_{1}+1, \cdots, \mathrm{n}$.

$$
\frac{\partial V_{i}}{\partial x} \geq 0 \quad\left(1, \mathrm{~L}, n_{1}\right), \frac{\partial V_{i}}{\partial x}<0 \quad\left(n_{1}+1, \mathrm{~L}, n\right) .
$$

In the communication between the corporation and the stakeholders the stakeholder i conveys the evaluation $\Phi_{\mathrm{i}}$ to it. This model analysis exhibits that $\Phi_{\mathrm{i}}$ represents net external cost with i and that it is positive for the positive stakeholder and negative for the negative stakeholder. The net profit of the corporation is expressed by increasing function $\Pi(\mathrm{x})$ of production activity $\mathrm{x}>0$. In the sustainability mechanism such as ESG and SDGs, the corporation is supposed to maximize the objective function

$$
\mathrm{NB}=\Pi(\mathrm{x})+\delta(\mathrm{y}) \sum_{\mathrm{i}=1}^{\mathrm{n}}\left\{\mathrm{V}_{\mathrm{i}}\left(\mathrm{x}, \mathrm{t}_{\mathrm{i}}\right)-\mathrm{y}_{\mathrm{i}}\right\}-\mathrm{t}-\sum_{\mathrm{i}=1}^{\mathrm{n}} \Phi_{\mathrm{i}}\left(\alpha_{\mathrm{i}}-\mathrm{V}_{\mathrm{i}}\left(\mathrm{x}, \mathrm{t}_{\mathrm{i}}\right)\right),
$$

regarding the $n+1$ variables $x, t_{1}, \cdots, t_{n}$. The optimal conditions with the first order differentiation of (6) is exhibited by (7) and (8). (7) and (8) are referred as the second best solution of sustainability.

$$
\begin{gathered}
\frac{d \Pi}{d x}=\sum_{i=1}^{n}-\left(\delta(y)+\frac{d \Phi_{i}}{d\left(\alpha_{i}-V_{i}\right)}\right) \frac{\partial V_{i}\left(x, t_{i}\right)}{\partial x}, \\
\frac{\partial V_{i}}{\partial t_{i}}=\frac{1}{\delta(y)+\frac{d \Phi_{i}}{d\left(\alpha_{i}-V_{i}\right)}}, i=1, \mathrm{~L}, n .
\end{gathered}
$$

We could explore how the sustainability mechanism works in the global community evolving with the recent in- 
dustrial revolution. Enlarging global community means that the number of stakeholder increases. Probably, the behaviors by the corporation to maximize profit might induce the market and government failures in the global community. We explore that the feature of sustainability solution depends on the balance of influences between the two types of stakeholders. To make clear the reasoning, the expression (7) is rewritten by

$$
\frac{d \Pi}{d x}=\sum_{i=1}^{n_{1}}-\left(\delta(y)+\frac{d \Phi_{i}}{d\left(\alpha_{i}-V_{i}\right)}\right) \frac{\partial V_{i}\left(x, t_{i}\right)}{\partial x}+\sum_{i=n_{1}+1}^{n}-\left(\delta(y)+\frac{d \Phi_{i}}{d\left(\alpha_{i}-V_{i}\right)}\right) \frac{\partial V_{i}\left(x, t_{i}\right)}{\partial x},
$$

and the right side of the above expression is divided into the two terms to present separately the positive and negative stakeholders.

The first best sustainability condition is considered by the comparison with the second best solution (7) and (8). Tanaka [23] supposed the first best situation that the evaluation with the performance of corporations are shared completely with the corporation and the stakeholders. This framework does not need incentive initiatives such as taxes and subsidies that construct the main pillars of the second best mechanism. The new objective function of maximization is expressed by

$$
\Pi(x)+\sum_{i=1}^{n} V_{i}\left(x, t_{i}\right)-t .
$$

The optimal solutions regarding (9) are referred as the first best conditions.

The first best conditions of sustainable community to be stated by (10) and (11) are contrasted as the second best conditions (7) and (8).

$$
\begin{aligned}
& \frac{d \Pi}{d x}=\sum_{i=1}^{n}-\frac{\partial V_{i}\left(x, t_{i}\right)}{\partial x}, \\
& \frac{\partial V_{i}\left(x, t_{i}\right)}{\partial t_{i}}=1, \quad i=1 \mathrm{~L}, n,
\end{aligned}
$$

are formed by the evaluations of different institutions and organizations and require the system to execute comparable and integrating marginal evaluations of the corporation and stakeholders. The first best solution is not likely to be identical with the second best one. We are obliged to manage to approach the optimal conditions (10) and (11) approximately using the second best framework.

\subsection{Governance of sustainable mechanism and the stakeholder dominance}

We can explore how the second best mechanism is possible to approximate efficiently to the first best conditions. The process to move the second best solution into the first best solution is achieved by controlling the altruistic and the risk coefficients effectively. We could evaluate the social surplus of the mechanism for sustainability to estimate the efficiency of the system. We assume that the second best solution is bound to approach to the first best solution. The total effort to maximize (1) is denoted by $\mathrm{y}^{*}$. Tanaka ${ }^{[35]}$ complements this paper and explores the social surplus where the second best solution can approximate the first best solution. In particular, the altruistic coefficient is not large enough to keep efficient communication in communities, but the incentive mechanism to approximate the first best lowers the risk coefficients. The previous research supposes that the total value of the risk coefficients retains in lower than unit and the second best expression (7) can approximate the first best one (10). The risk coefficients make effects positively in critical situations. In this case, the risk coefficients exhibit the initiatives to move toward sustainability. This paper considers how the gap between the two solutions happens actually. The stakeholders obtain diverse evaluations for the corporation. Although the risk coefficients are expected to present various values, to simplify the discussion we suppose that the inequalities

$$
1<\delta\left(y^{*}\right)+\frac{d \Phi_{i}}{d\left(\alpha_{i}-V_{i}\right)}, \quad \mathrm{i}=1, \ldots, \mathrm{n},
$$

are satisfied with for all stakeholder i. 
cost and benefit

A

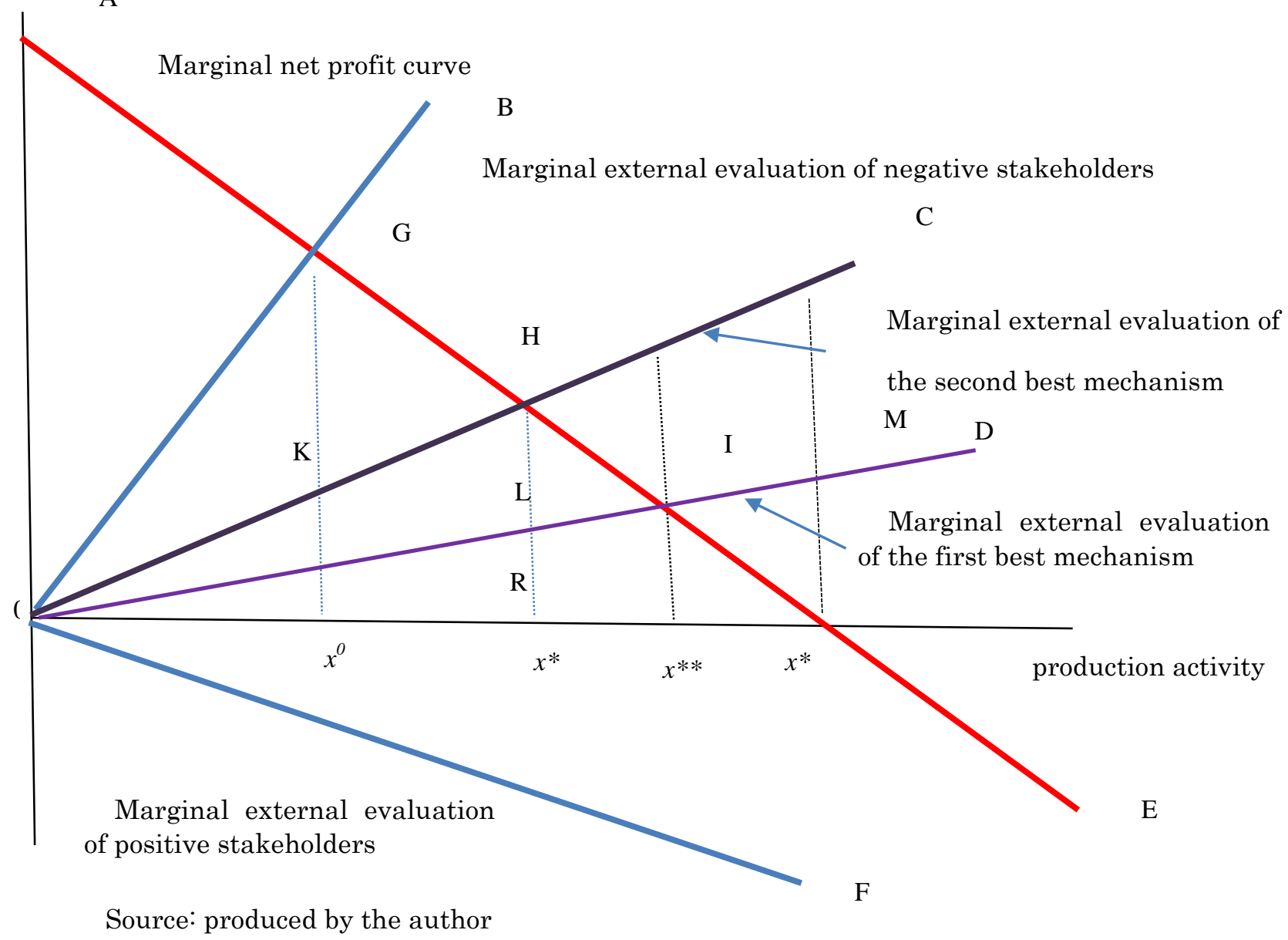

Figure 1. The sustainability mechanism under dominant negative stakeholders

The relation between the positive and negative stakeholders influences differently on the features of the mechanism for sustainability. This paper explores separately the effect of the mechanism for sustainability in the two following situations. In the first situation where the total marginal evaluation of the negative stakeholders exceeds that of the positive stakeholders, Figure 1 illustrates how the mechanism for sustainability improves the social welfare. The total marginal evaluation of stakeholders to exhibit the right side of (10) is denoted by the curve 0D. The left side of (10) denotes the marginal profit curve AJ. The total marginal evaluations of the negative stakeholders and the positive stakeholders are expressed by the curves $0 \mathrm{~B}$ and $\mathrm{OF}$. The right side of (7) in the second best solution presents the total marginal evaluation curve by the both stakeholders $0 \mathrm{C}$. The first best and the second best solutions are indicated by the points I and $\mathrm{H}$. The product activities of the first best and the second best are equal to $\mathrm{x}^{* *}$ and $\mathrm{x}^{*}$ to be less than the activity of the market equilibrium $\mathrm{x}^{* * *}$. The negative stakeholder seeks the point $\mathrm{C}$ with quantity $\mathrm{x}^{0}$ to be less than $\mathrm{x}^{*}$ and $x^{* *}$. In this context, we could analyze the cost and benefit of the mechanism for sustainability. The second best solution gains the social surplus to be measured by the area to subtract the area of triangle HRJ from the area of trapezoid LRJM when the area of the triangle HLI is larger than the area of the triangle IJM. The second best solution $\mathrm{H}$ loses the social surplus with the area of the triangle HLI in comparison with the first best solution. To construct the mechanism for sustainability is proved theoretically to yield the social surplus in comparison with a market solution. When the external evaluation by the negative stakeholders exceed largely the value by the positive stakeholders, the mechanism of sustainability lowers the production of the corporation.l The theoretical exploration evaluates affirmatively some mechanisms for sustainability in practice such as ESG to be designed and developed.

Figure 2 shows the second situation where the total marginal evaluation of the positive stakeholders is assumed to exceed that of the negative stakeholders. The negative and positive stakeholders aim independently at own optimal 
point $\mathrm{G}$ and $\mathrm{K}$. The positive stakeholder is supposed to gain cooperative benefits from the external effects of the corporation or the organization. The positive stakeholder obtains the positive marginal social benefit to be depicted as the negative marginal social cost. In Figure 2, the vertical distance between the curve of marginal profit AF and the curve of marginal social cost $0 \mathrm{C}$ presents social marginal net benefit. The net social benefit is maximized at the point I. In the second best solution, the mechanism of sustainability designs for the corporation to estimate the curve 0D to approximate the curve $0 \mathrm{C}$ and the equilibrium is exhibited by the point $\mathrm{J}$. The dominance of the positive net social benefit takes the second best production $\mathrm{x}^{* *}$ to exceed the market production $\mathrm{x}^{* * *}$.

cost and benefit

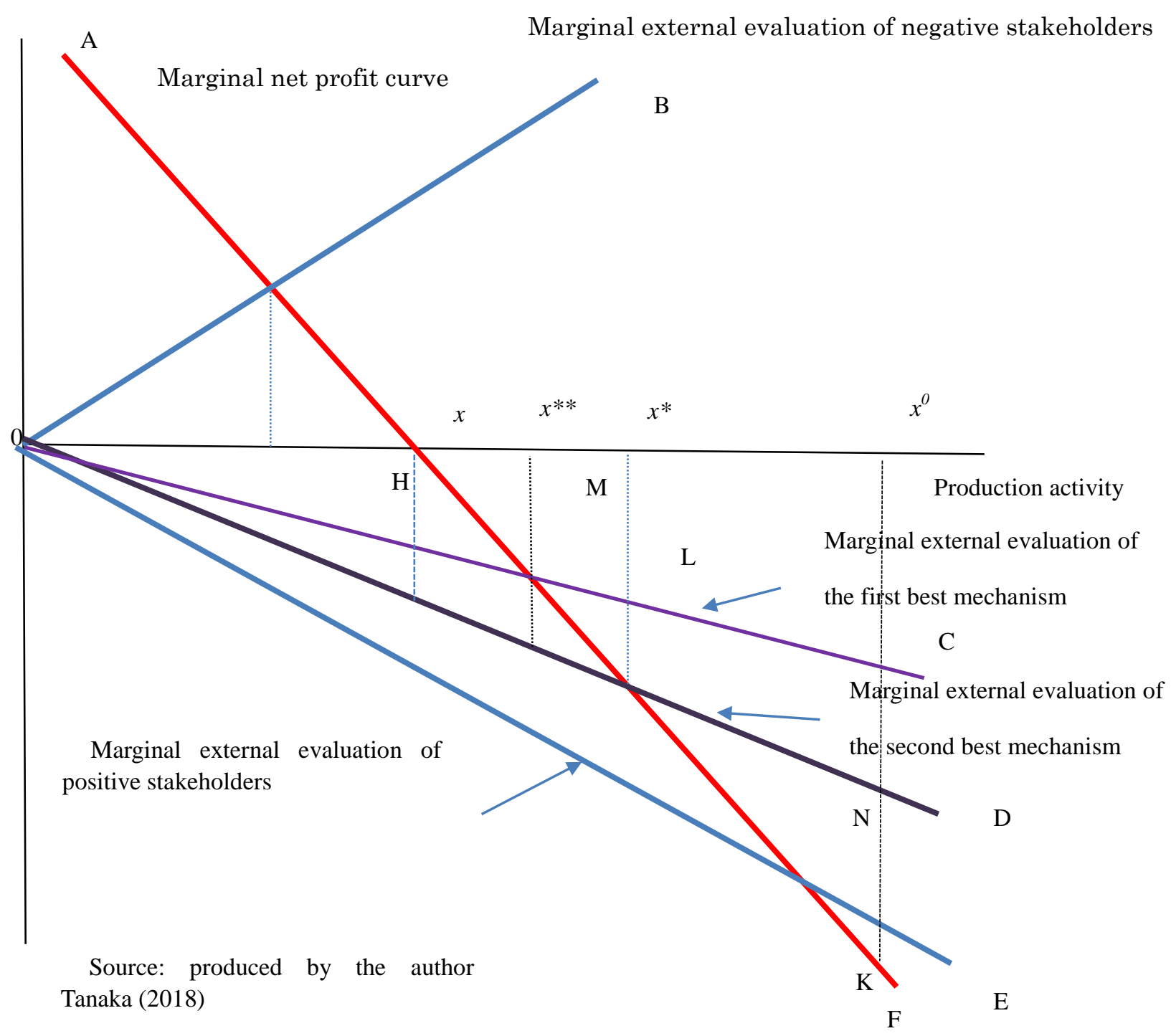

Figure 2. The sustainability mechanism under dominant positive stakeholders

By moving from the market solution $\mathrm{H}$ to the second best solution $\mathrm{J}$, the mechanism for sustainability is required to compensate the decrement of the profit presented by the area of the triangle HJQ but obtains net social surplus indicated by the area to subtract the triangle the triangle HJQ from the trapezoid HNLQ. When the area of the triangle HNI is larger than the triangle IJL, the mechanism obtains the positive surplus. The second best mechanism for sustainability enhances or discourages the activities of corporations by depending on the relative dominance between the marginal external evaluations of the positive and negative stakeholders. The results in Section 3 are summarized in Proposition 2.

Proposition 2 . The mechanism for sustainability supported by the appropriate combination of the altruistic and risk coefficients obtains the second best solution and can improve social welfare. The mechanism for sustainability under the dominance of the positive stakeholders increases the production of the corporation production over the market solu- 
tion. The mechanism for sustainability under the dominance of the negative stakeholders decreases the production of the corporation production under the market solution.

\section{The new industrial revolution and influences of negative stakeholders}

The previous section demonstrates theoretically that construction of the mechanism for sustainability can increase social welfare in the global communities. Consequently, the result implies that the voluntary and cooperative structure of the mechanism constructed by many stakeholders can contribute to improve social welfare of the global communities. However, the mechanism appears to influence the corporation differently by depending on the relative total evaluations of the negative and positive stakeholders in the region to be located. Figure 2 illustrates explicitly that the mechanism for sustainability initiates the vitalization of the community where the corporation to obtain the prevailing the total evaluation of the positive stakeholder against that of the negative stakeholder of the corporations. On the contrary, Figure 1 prospects that the mechanism leads to shrink the region where the corporations with more total evaluation by the negative than positive stakeholders prevail. Proposition 2 states the possibility that the mechanism for sustainability is expected to promote the replacement of industrial structure by depending on the signs in the right side of (7)'. The following discussion is supposed to be derived simply from the previous relationships. If the mechanism for sustainability becomes to be more complete, the region connected closely with many positive stakeholders will grow steadily, but the region to be accommodated with many negative stakeholders will be restrained from the above.

Figure 3 illustrates the two corporations to belong in indifferent industries. In the 4 left boxes of Figure 3, the corporation exhibits contributes positively on the region A but negatively on others B,C,D. The corporation in the 4 right boxes contributes by lesser scale on the all regions but negative evaluation appears only in region A. The account by (7)' shows that the corporation in right side is placed in the negative dominant; 5-8=-3. By using the explanation in Figure 1, the mechanism of sustainability works to decline this type of corporation. The regions where the shrinking industries concentrate tend to lower vitalities. On the contrary, the (7)' in the right side is the positive value; 5-2=2. As Figure 2 illustrates, the mechanism of sustainability raises the performance of the corporation. Initiatives to propel the innovation of technologies in this regional corporations make possible to enhance the regional vitalization.

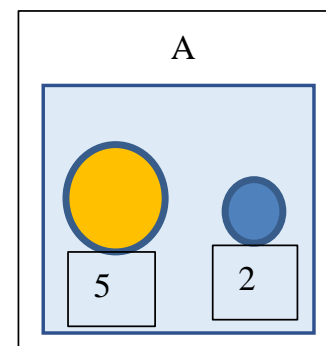

C

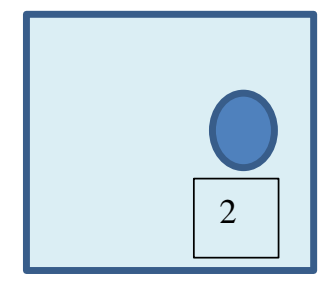

Donimance of Negative Stakeholders

B

$\mathrm{D}$
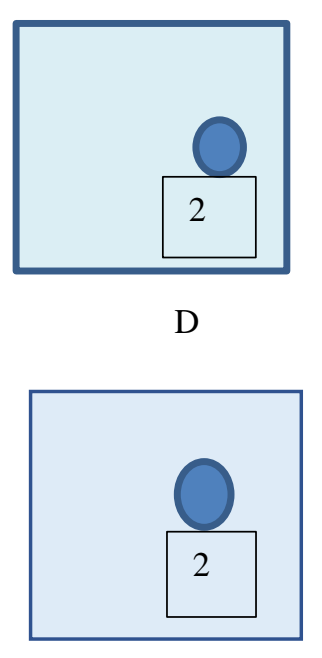

(1)

O; Term of Positive Stakeholders (7)'.

Source; produced by authors

A

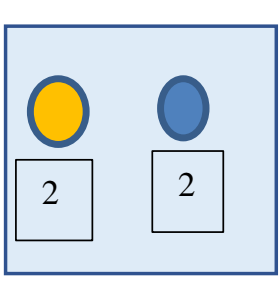

C

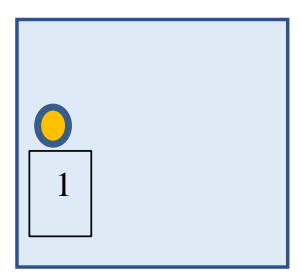

Donimance of Positive Stakeholders
B

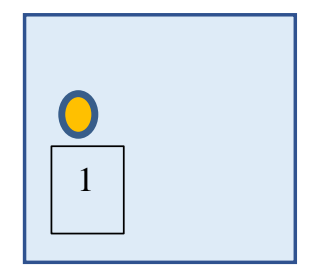

$\mathrm{D}$

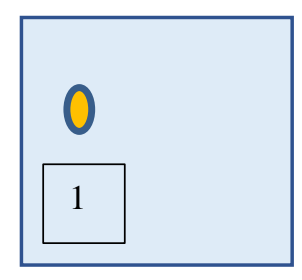


The innovation of technologies such as ICT, AI and IoT prospects to reform the connecting structure between the corporation and the stakeholders. The corporation is probable to observe both positive and negative stakeholders changing. In some noticeable situations, the divergences between market and sustainability solutions in Figure 1 and Figure 2 widens and fundamental change in the stakeholders moves the sustainability solutions rapidly and greatly. In the first, the global economies enlarge the spatial influence of the corporation and increase the negative stakeholders. In particular, the corporation becomes to be obliged to cope with the problems in the environment and to observe the principle of corporate governance. In the second, the innovation of intelligent technologies constructs the smart network of transportation and facilitates the two way connection with consumers and the corporation. The enhancement of influence with the positive stakeholders can lead to grow production of the corporation. The structural changes in the stakeholder project surely to raise the welfare loss brought by market solutions. The mechanism of sustainability is needed to reduce the welfare loss.

The corporations to lead the forth industrial revolution develop a new market structure by using the internet. This market structure should accompany the legal and ethical foundation to be acceptable by virous stakeholders. The mechanism for sustainability aims to promote the communication between the stakeholders and the corporation. When this mechanism could proceed to the global foundation on the sustainability, the corporations obtains a new scope of stakeholders. The enlarged stakeholders shift the rate between the negative and positive stakeholders for many corporations. The mechanism for sustainability selects more apparently to decline the production activities of the corporation in Figue1 and to grow production of the corporation in Figure 2. The mechanism vitalizes indirectly the regions located by the major corporation to be connected with many positive stakeholders. If the new industrial revolution increases positive stakeholders more than the negative stakeholders, the mechanism for sustainability prompts to accelerate the progress of the forth industrial revolution. The dominance between positive and negative stakeholders does not appear equally in many regions, but might feature prosperity and decline of each region. Eventually, the mechanism makes influences on the vitalization and structural change of the region. Although many researchers such as Friedmann ${ }^{[7,8]}$, Kennedy ${ }^{[10]}$ and Short ${ }^{[19]}$ explore the issues for soft and hard resources to concentrate on the global cities, in this paper we discuss the mechanism for sustainability to govern global communities.

Proposition 3 Progress of sustainability mechanism makes effects positively on region covered by the corporations with dominant positive stakeholders, but declines the region with major corporations to be connected with negative stakeholders. The mechanism of sustainability can contribute the stability of the global communities but may diversify regional performances.

\section{Concluding remarks}

The mechanism for sustainability reduces the global risks of instability and crisis brought by globalized economies. To achieve the purpose the mechanism provides the method of evaluation and initiatives to manage the global sustainable communities. We will explore the impact on methods of the mechanism in proceeding innovation of the intelligence industry. This approach should explore the effective way to construct massive structure of financial services.

In the first, some growing corporations such as Google, Apple, Facebook, Amazon obtain and operate the highly developed technology of internet. The growing corporations have developed the new positive and negative stakeholders at the same time. However, the communication system is not complete in the first stage of the growing network. The agreements regarding international business and local regional issues need to integrate the related fields properly. The practical learning brings the arrangement of the communication system and becomes to estimate accurately the altruistic and risk coefficients. The second best solution will prevent the global economic and social systems from becoming unsustainable.

In the second, the mechanism for sustainability suggests the guide line on provision of social infrastructure. The innovation of ICT technologies makes possible to offer the corporation opportunities to move the sites of production. If the mechanism for sustainability can cover simultaneously some local regions, the corporation is possibly to decline the spending on infrastructure and to decrease the contribution $t_{i}$ on the regional infrastructure on the region defined by $i$. In the mechanism the altruistic coefficient improves and the freeriding behavior by the corporation raises the risk coefficients. Figure 2 means that the mechanism requires the corporation to increase output $\mathrm{x}$ far beyond the market solu- 
tion of the point $\mathrm{H}$ to decrease the private net profit. The increasing production benefits to many regions beyond the region i. Even if the corporation lowers the burden on infrastructure, it is ought to pay another contribution on the community.

\section{References}

1. Andreoni J. Impure Altruism and Donations to Public Goods: A Theory of Warm-Glow Giving. Economic Journal 1990; 100, pp. 464-477.

2. Arrow KJ. Social Responsibility and Economic Efficiency. Public Policy 1973; 21,pp.303-317.

3. Becchetti L, Borzaga C. The Economics of Social Responsibility: The world of social enterprises. London: Routledge; 2010.

4. Becker GS. A Theory of Competition Among Pressure Groups for Political Influence. Quarterly Journal of Economics 1983; 1, pp. 371-400.

5. Becker GS. Public Policies, Pressure Groups, and Dead Weight Costs. Journal of Public Economics 1985; 28, pp.329-347.

6. Bührs T. Environmental Integration: Our Common Challenge. New York, State University of New York Press; 2009.

7. Friedmann J. The World City Hypothesis, Development and Change 1986; 17,(1), pp.69-83.

8. Friedmann J. Prospect of Cities, Minneapolis. University of Minnesota Press; 2002.

9. GSIA. Global Sustainable Investment Review 2016, GSIA; Global Sustainable Investment Alliance 2017. [cited 2018 April 2] http://www.gsi-alliance.org/.

10. Kennedy C. The Evolution of Great World Cites: Urban Wealth and Economic Growth; Questioning Cities Series. Toronto, Buffalo and London, University of Toronto Press; 2011.

11. Komninos N. Intelligent Cities and Globalisation of Innovation Networks. Routledge, London and New York; 2008.

12. Leigh NG, Blakely EJ. Planning Local Economic Development: Theory and Practice. (Fifth Edition), Los Angeles, Sage Publications;2013.

13. May T, Perry B. Cities and the knowledge Economy: Promise, Politics and Possibilities. Routledge, London and New York;2018.

14. McLaren D, Agyeman J. Sharing Cities: A Case for Truly Smart and Sustainable Cities. The MIT Press, London; 2015.

15. Richardson HW, Nam CW(eds). Shrinking Cities: A Global Perspective. Routledge, London and New York; 2014.

16. Rifkin J. The Zero Marginal Cost Society: The internet of Things, The Collaborative Commons, and The Eclipse of Capitalism. St. Martin’s Press, New York; 2014.

17. Roberts RD. A Positive Model of Private Charity and Public Transfers. Journal of Political Economy1984;92, pp.136-148.

18. Roubini N, Mihm S. Crisis Economics: A Crash Course in the Future of Finance. Penguin Press, New York; 2010.

19. Short JR. Global Metropolitan: Globalizing Cities in a Capitalist World. London and New York, Routledge;2004.

20. Sturzaker J, Mell I. Breen Belts: Past; present; future? London and New York, Routledge; 2017.

21. Tallon A. Urban Regeneration in the UK, Second Edition, London, Routledge; 2013.

22. Tanaka H. Redistribution Tax under Non-benevolent Government. Public Choice 1998; 96, pp.325-345.

23. Tanaka H. Kigyo no Syakaiteki Sekinin no Keizai Riron (Japanese) [Theoretical Analysis for Corporate Social Responsibility]. Tikyuu Kankyu Report (Japanese) [Global Environmental Policy in Japan] 2004; 9, pp 1-9.

24. Tanaka H(ed.). Jizokukanouna Chiiki Syakai Jitugen eno Keikaku to Senryaku (Japanese) [Initiatives for the Sustainable Regional Community], Chuo University Press; 2006.

25. Tanaka H. The Sustainable Framework for Climate Change and the Financial Crisis 2008-2009.” Long Finance and London Accord 2009; [cited 2018 July 15]; The institute of Economic Research, Chuo University, Discussion Paper,2009.No.134 pp.1-18.

http://www.longfinance.net/component/yuidt/index.php?option=com_content\&view=article\&id=214\&Itemid=157.

26. Tanaka H. Sustainability and Network Effects in Global Cities. Long Finance and London Accord 2011; [cited 2018 July15], pp.1-24.

http://www.longfinance.net/programmes/london-accord/396-report-template.html

27. Tanaka H. Social Responsibility, Social Enterprise and Social Innovation in the Stakeholder Communities. Long Finance and London Accord 2012; [cited 2018 July15],pp.1-16.

www.longfinance.net/programmes/financialcentrefutures/london-accord.html?id=613

28. Tanaka H. A Theoretical Model Analysis of Urban Transformation after Global Financial Crisis 2008,” Long finance and London Accord 2013; [cited 2018 July15], pp.1-18. http://www.longfinance.net/component/longfinance/?view=report\&id=397

29. Tanaka H. Cooperative and Competitive Urban Municipality Policies in the Tokyo Area to Target Transforming Community Needs,” Long finance and London Accord 2016; [cited 2018 July15], pp.1-19, 
http://www.longfinance.net/component/longfinance/?view=report\&id=463

30. Tanaka H. The Finance System as Global Public Goods and the Regeneration of Global Communities. Long Finance and London Accord 2016; [cited 2018 July15], pp.1-12.

http://www.longfinance.net/programmes/financialcentrefutures/london-accord.html?id=402.

31. Tanaka H, Tanaka C. Urban Reform and Shrinking City Hypotheses on the Global City Tokyo, Long finance and London Accord 2016; [cited 2018 July15]pp.1-18, http://www.longfinance.net/component/longfinance/?view=report\&id=548

32. Tanaka H. The Sustainability Theorem in the ESG Mechanism. Long Finance and London Accord 2016; [cited 2018 July15] pp,1-29. http://www.longfinance.net/images/reports/pdf/Tanaka-The-Sustainability-Theorem-in-the-ESG-Mechanism-2017. pdf.

33. Tanaka H.(ed.) Global Community Governance, Research Papers No5, The institute of Economic Research, Chuo University, 2016.[cited 2018 July15] http://www.chuo-.ac.jp/research/institutes/economic/publication/research/

34. Tanaka H. Sustainability of Global Communities and Regional Risk Governance. Asia Pacific Journal of Regional Science 2017; 1, pp.639-653.

35. Tanaka H. Jizyen no Jizokukanousei to Chiikikatuseika no Kakusa (Japanese) [The Second Best Framework of Sustainability and Diversified Regional Vitalization] The Annual of the Institute of Economic Research Chuo University 2018; 50, pp.249-267

36. Tirole J. Corporate Governance. Econometrica 2001; 68(1), pp.1-35.

37. UNEP FI and UN Global Compact. Responsible investment and hedge funds: A discussion paper,2006. [cited 2018 July15. https://www.unpri.org/download_report/3972. 